Gut, 1986, 27, 1035-1042

\title{
Identification of pancreas necrosis in severe acute pancreatitis: imaging procedures versus clinical staging
}

\author{
S BLOCK, W MAIER, R BITTNER, M BÜCHLER, P MALFERTHEINER, \\ H G BEGER \\ From the Surgical and Radiological Departments, University of Ulm, Ulm, Federal Republic of Germany
}

SUMMARY One hundred and five of 395 patients with acute pancreatitis were surgically treated in our clinic from 1981 to 1984 . Ninety three of these patients were examined with contrast enhanced computed tomography and/or ultrasound and were clinically assessed according to Ranson's objective criteria before operation. At operation, 77 patients showed necrotising pancreatitis and 16 showed biliary acute interstitial pancreatitis. Ninety per cent of the cases with extensive and $79 \%$ of those with minor necroses of the pancreas had been demonstrated with contrast enhanced computed tomography. Ultrasound failed to be diagnostic in $24 \%$ of the patients due to meteorism; the sensitivity of the diagnostic studies for pancreatic necrosis was $73 \%$ regardless of the extent of the process. Using the early objective signs, seven patients with acute interstitial pancreatitis were classified as having a severe attack, whereas 30 patients with necrotising pancreatitis were categorised as mild attacks. We conclude that the contrast enhanced computed tomography is an aid in deciding on conservative or surgical treatment in a case of acute pancreatitis. Ultrasound does not appear to be an adequate method for determining pancreatic necrosis. The early objective signs fail to sufficiently identify the necrotising form of acute pancreatitis.

Even severe cases of acute pancreatitis can be cured by medical therapy if they are restricted to interstitial inflammation. Necrotising pancreatitis, however, holds a high risk of local infection and generalised sepsis and can, if it involves larger areas of the pancreas, lead to retroperitoneal tissue invasion and progressive toxic organ complications. ${ }^{1-3}$ These complications could be avoided by the surgical removal of necrotic tissue and exudate. ${ }^{2-6}$ This in turn poses the problem of identifying and quantifying the necrosis of the pancreas in time for a successful operation. We therefore conducted a prospective clinical study in which the capacity of contrast enhanced computed tomography, ultrasound, and early objective signs ${ }^{7}$ to assess necrotising pancreatitis was determined by comparing the

Address for correspondence: H G Beger, M D, FACS, Head of the Department of General Surgery, University of Ulm, Steinhövelstrasse 9, 7900 Ulm, FRG.

Received for publication 13 December 1986. preoperative evaluations furthered by these methods with the intraoperative findings.

\section{Methods}

\section{PATIENTS}

Three hundred and ninety five patients were treated for acute pancreatitis from 1981 to $1984 ; 163$ of these were admitted to the surgical ward for a severe or complicated course of the disease, 105 were surgically treated. Half the patients were referred from outlying clinics. Surgery was indicated when necrotising pancreatitis was suggested by organ failures resistant to therapy and/or laboratory findings of severe acute pancreatitis combined with increasing or persistent abdominal symptoms and when acute cholecystitis caused by gall stone disease was simultaneously present. Ninety three patients were included in a prospective study of diagnostic methods. Twelve patients were excluded because of equipment failure or emergency laparotomy. The com- 
puted tomography and ultrasound studies were evaluated on a routine basis.

BIOlOgical AND AETIOlOgical DATA

The average age of the patients was 46 years (17-83) Sixty one patients $(65 \cdot 6 \%)$ were men, 32 patients $(34.4 \%)$ women. The aetiologically relevant factors were alcohol abuse in $41(44.1 \%)$, gall stones in $27(29.0 \%)$ and trauma in four (4.3\%) patients; the aetiology was unclear in 21 $(22.6 \%)$ patients. Alcohol abuse was noted as an additional aetiological factor in four of the patients with gall stones $(14 \cdot 8 \%)$.

\section{IMAGING PROCEDURES}

Seventy seven patients were examined with computed tomography, 75 with ultrasound, and 59 patients with both. The computed tomography used was either Somatom 2 (Siemens) or GE CT/T8800. Each patient received $200 \mathrm{ml}$ of water soluble contrast medium by mouth, scans were then done before and after the $\mathrm{i} v$ administration of contrast medium. The slice thickness was $5 \mathrm{~mm}$, exposure time 12 seconds. The systems sector scan Siemens, the linear array scan Imager 3001 ATL or the MK 100 ATL were used for the ultrasound examinations.

CLINICAL CLASSIFICATION AND DATA

All 93 patients were clinically assessed and shown to have signs and symptoms of complicated acute pancreatitis after their admission to the surgical ward. Sixty five patients $(69.9 \%)$ had systemic complications. Pulmonary insufficiency $\left(\mathrm{pO}_{2}<60\right.$ $\mathrm{mmHg}$ ) occurred in 39 patients, acute renal insufficiency (serum creatinine $>1.4 \mathrm{mg} / \mathrm{dl}$ ) in 27 , shock (systolic blood pressure $<80 \mathrm{~mm} \mathrm{Hg}$ ) in 13 and sepsis (body temperature $>38.5^{\circ} \mathrm{C}$, chills, metabolic acidosis, platelet reduction, raised WBC in 18 patients. A paralytic ileus was found in 13 patients, eight patients had gastrointestinal bleeding. Eighty seven patients presented with leukocytosis, 60 with raised blood sugar concentrations LDH was raised in 35 of the 68 patients in whom it was determined and 51 of 78 patients had hypoalbuminaemia of less than $3.5 \mathrm{~g} / \mathrm{dl}$. These parameters were not determined in 25 and 15 patients, respectively, because the routine laboratory protocol was not followed on admission. Serum amylase was raised in 75 patients.

The clinical data were then reviewed for the criteria of Ranson's objective signs ${ }^{7}$ and the patients classified accordingly as having 'mild' or 'severe' acute pancreatitis. Ten of the 11 objective criteria were evaluated; fluid sequestration ( $>6 \quad 1 / 24 \mathrm{~h})$ was omitted because of the difficulty involved in assessing it accurately. Except for the LDH mentioned above and the serum calcium, which was not determined in two patients, all 10 criteria were completed in each patient. The Ranson criteria were calculated in 45 secondary referral patients $(48.4 \%)$.

We do not consider these criteria as prognostic signs, but as an abbreviated formula for clinical severity which, in conjunction with the imaged morphological findings, provides an impression of the urgency of surgical intervention.

\section{MORPHOLOGICAL CLASSIFICATION AND DATA}

The pancreas was exposed ventrally and the adjacent structures and retroperitoneal spaces were inspected. The necrotic tissue was either manually or instrumentally removed and the extent of the pancreatic necrosis determined by the weight and dimensions of the extracted pancreatic tissue: tissue of up to $3 \times 5 \mathrm{~cm}$ and $50 \mathrm{~g}$ was classified as a $30 \%$ necrosis, tissue of up to $5 \times 8 \mathrm{~cm}$ and $120 \mathrm{~g}$ as a $50 \%$ necrosis, necrosis involving the entire pancreas and weighing more than $120 \mathrm{~g}$ was graded as subtotal, a weight of over $190 \mathrm{~g}$ was considered a total pancreatic necrosis. Only two categories were used for the purpose of this study - that is, minor necrosis and extensive necrosis. The latter refers to pancreatic necrosis of $50 \%$ to $100 \%$, which was found to be associated with a significantly higher morbidity. ${ }^{4}$ Specimens of the removed necrotic tissue were submitted for histological evaluation. The samples revealed both necrotic pancreas as well as fatty tissues. Although the categories mentioned above are thus based on approximate values only, they are, as demonstrated by Beger et al, ${ }^{4}$ nevertheless of clinical relevance.

Minor necrosis of the pancreas was found in 35 $(45.4 \%)$, and extensive necrosis in 26 patients $(33.8 \%)$. Sixteen of the latter presented with subtotal or total necrosis. Bacteriological samples were submitted in 58 cases, of which $23(39.7 \%)$ showed bacterial contamination of the necrotic tissue at the time of operation. Additional findings and their relationship to the morphological categories are listed in Table 1.

\section{SURGICAL PROCEDURES AND RESULTS}

Debridement and postoperative continuous local lavage with additional peritoneal lavage in cases of peritonitis were carried out in most of the patients. In patients with gall stone disease, cholecystectomy and/or choledochotomy with $\mathrm{T}$-drainage was done simultaneously. Biliary surgery was combined with pancreatic drainage in patients with biliary acute interstitial pancreatitis. The postoperative lavage of the necrotised area in the retroperitoneal space was continued until the drainage fluid no longer showed tissue debris and microorganisms. The lavage period averaged $24(10-115)$ days. 
Table 1 Intraoperative pathomorphological findings

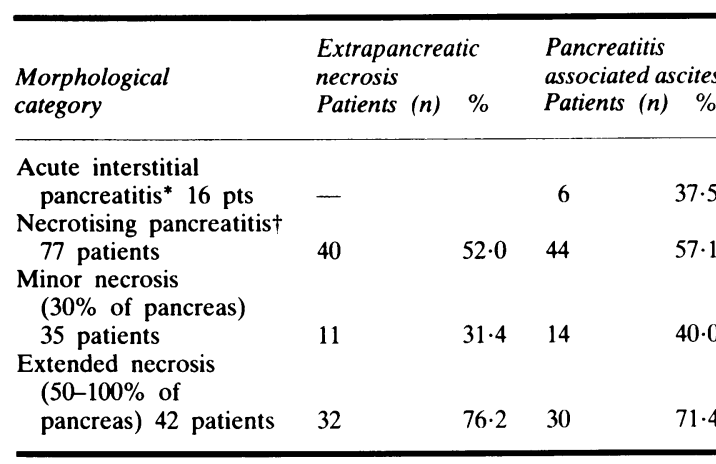

${ }^{*}$ Acute interstitial pancreatitis

†Necrotising pancreatitis.

Five patients with necrotising pancreatitis $(6 \cdot 5 \%)$ and one patient with acute interstitial pancreatitis $(6 \cdot 3 \%)$ died during the postoperative period. The median of the postoperative hospital stay was 26 (minimum:1-maximum:116) days (survivals: 26, deaths: 25 days), that of the intensive care period was three $(0-42)$ days (survivals: three deaths: 11 days).

\section{STATISTICAL EVALUATION}

Sensitivity (correct positives: correct positives + false negatives) was the category used to evaluate the results of the computed tomography and ultrasound examinations.

\section{Results}

CONTRAST-ENHANCED COMPUTED TOMOGRAPHY Of the 77 patients examined with computed tomography, 10 suffered from acute interstitial pancreatitis, 67 from necrotising pancreatitis. Twenty nine patients showed minor necrosis of the pancreas, 38 showed extensive necrosis (Tables 2 and 3).

Necrotising pancreatitis was determined in $85.1 \%$ of the patients. The extent of the pancreatic necrosis was correctly assessed in $72.4 \%$ of the minor and in $65.8 \%$ of the extensive necrotising processes. Minor necroses were overestimated in $6.9 \%$, a false negative interpretation as acute interstitial pancreatitis was made in $20.7 \%$ of the patients. In $23.7 \%$ of the patients, extensive necroses were interpreted as minor processes, whereas $10.5 \%$ of the diagnoses were false negative (Table 3 ). As a whole, the necrotising process as such was identified more often in patients with an extensive necrosis $(89.5 \%)$ than in patients with minor necrosis of the pancreas $(79 \cdot 3 \%)$.
Table 2 Assessment of pancreas necrosis by contrastenhanced computed tomography

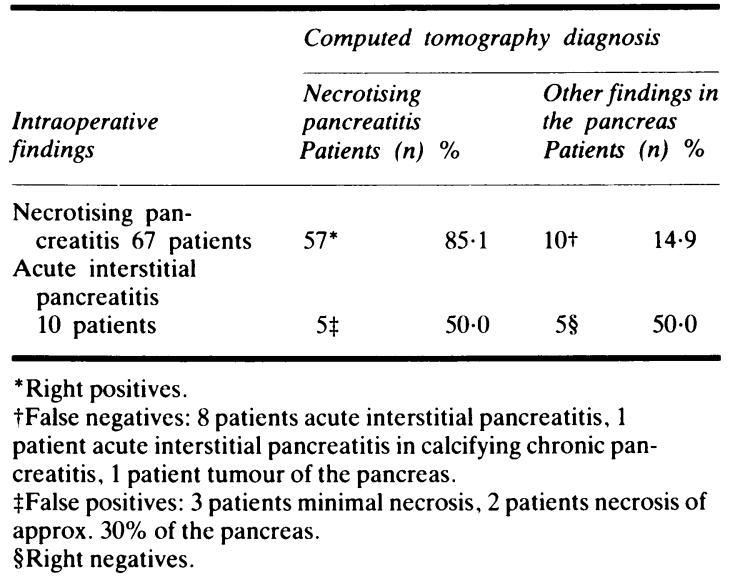

Table 3 Assessment of pancreas necrosis of different extent by contrast enhanced computed tomography

\begin{tabular}{|c|c|c|c|c|c|c|}
\hline \multirow[b]{2}{*}{$\begin{array}{l}\text { Intra- } \\
\text { operative } \\
\text { findings }\end{array}$} & \multicolumn{6}{|c|}{ Computed tomography diagnosis } \\
\hline & $\begin{array}{l}\text { Minor } \\
\text { necrosis } \\
\text { Patients (n) }\end{array}$ & $\%$ & $\begin{array}{l}\text { Extended } \\
\text { necrosis } \\
\text { Patients (n) }\end{array}$ & $\%$ & $\begin{array}{l}\text { Other } \\
\text { in the } \\
\text { Patients }\end{array}$ & $\begin{array}{l}\text { findings } \\
\text { pancreas } \\
s(n) \%\end{array}$ \\
\hline $\begin{array}{l}\text { Minor } \\
\text { necrosis* } \\
29 \text { patients }\end{array}$ & 21 & $72 \cdot 4$ & 2 & $6 \cdot 9$ & 6 & $20 \cdot 7$ \\
\hline $\begin{array}{l}\text { Extended } \\
\text { necrosis }{ }^{\dagger} \\
38 \text { patients }\end{array}$ & 9 & $23 \cdot 7$ & 25 & $65 \cdot 8$ & 84 & $10 \cdot 5$ \\
\hline
\end{tabular}

*approx. $30 \%$ of the pancreas.

$+50 \%$ to $100 \%$ pancreas.

Necrotising pancreatitis was also suspected in five of the 10 patients with acute interstitial pancreatitis - that is, as minimal necrosis in three, as a $30 \%$ necrosis in two cases, but no pancreatic necrosis was found intraoperatively. It is noteworthy, however, that there was no false positive diagnosis of an extensive pancreatic necrosis.

\section{ULTRASOUND}

Seventy five patients were examined with ultrasound. Sixty two patients suffered from necrotising pancreatitis, 13 from severe acute interstitial pancreatitis. The necrotising process was minor in 26 , extensive in 36 patients (Tables 4 and 5).

The examinations turned out to be non-diagnostic in 18 patients $(24.0 \%)$ because of bowel gas collections; this was the case in one-third of the patients with a vast necrotic area. As a whole, only $56.4 \%$ of 
Table 4 Assessment of pancreas necrosis by ultrasound

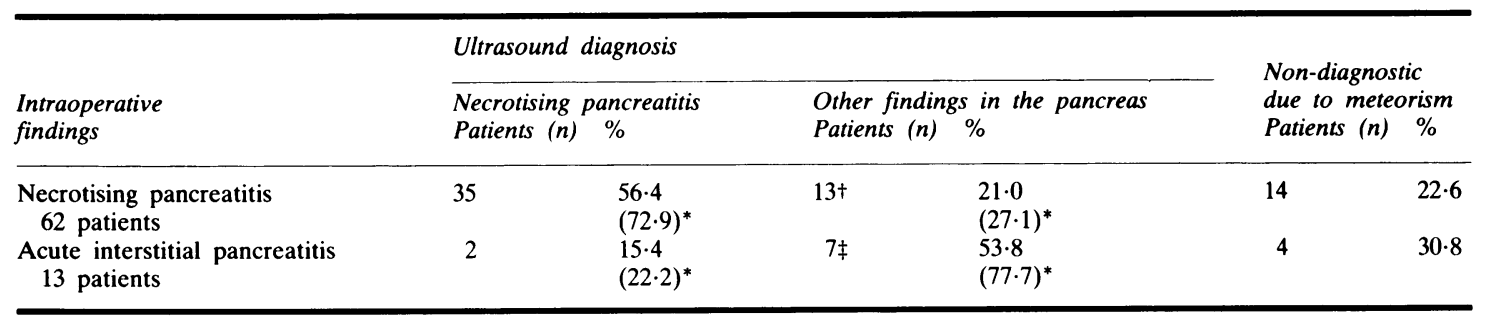

*Percentage of the diagnostic studies

$\dagger 11$ patients acute interstitial pancreatitis, 1 patient calcifying chronic pancreatitis, 1 patient normal pancreas.

$\ddagger$ four patients acute interstitial pancreatitis, 3 patients normal pancreas.

Table 5 Assessment of pancreas necrosis of different extent by ultrasound

\begin{tabular}{|c|c|c|c|}
\hline \multirow[b]{2}{*}{$\begin{array}{l}\text { Intraoperative } \\
\text { findings }\end{array}$} & \multicolumn{2}{|l|}{ Ultrasound diagnosis } & \multirow{2}{*}{$\begin{array}{l}\text { Non-diagnostic } \\
\text { due to meteorism }\end{array}$} \\
\hline & $\begin{array}{l}\text { Necrotising pancreatitis } \\
\text { Patients }(n) \%\end{array}$ & $\begin{array}{l}\text { Other findings in the pancreas } \\
\text { Patients (n) } \%\end{array}$ & \\
\hline $\begin{array}{l}\text { Minor necrosis* } \\
26 \text { patients }\end{array}$ & $\begin{array}{l}69 \cdot 2 \\
(75.0)^{*}\end{array}$ & $\begin{array}{l}23 \cdot 1 \\
(25 \cdot 0)^{*}\end{array}$ & $7 \cdot 7$ \\
\hline $\begin{array}{l}\text { Extended necrosis } \dagger \\
36 \text { patients }\end{array}$ & $\begin{array}{l}47 \cdot 2 \\
(70 \cdot 8)^{*}\end{array}$ & $\begin{array}{l}19 \cdot 4 \\
(29 \cdot 2)^{*}\end{array}$ & $33 \cdot 3$ \\
\hline
\end{tabular}

*Percentage of the diagnostic studies

†The rate of non-diagnostic studies correlated significantly with the extent of the pancreatic necrosis according to the increasingly frequent paralysis of the intestines causing bowel gas collections. Minor and extended necroses were usually not differentiated in the study reports.

Table 6 Clinical staging in 93 patients with acute interstitial pancreatitis or necrotising pancreatitis

\begin{tabular}{|c|c|c|c|c|c|}
\hline \multirow[b]{2}{*}{ Morphological category } & \multicolumn{4}{|c|}{ Objective signs $(n)$} & \multirow[b]{2}{*}{ Mean value } \\
\hline & $\begin{array}{l}0-2 \\
\text { Patients (n) }\end{array}$ & $\%$ & $\begin{array}{l}3-10 \\
\text { Patients (n) }\end{array}$ & $\%$ & \\
\hline \multicolumn{6}{|l|}{ Acute interstitial pancreatitis } \\
\hline 16 patients & 9 & $56 \cdot 2$ & 7 & $43 \cdot 8$ & $2 \cdot 8$ \\
\hline \multicolumn{6}{|l|}{ Necrotising pancreatitis } \\
\hline 77 patients & 30 & $39 \cdot 0$ & 47 & $61 \cdot 0$ & $4 \cdot 0$ \\
\hline \multicolumn{6}{|l|}{ Minor necrosis $(30 \%$ of pancreas) } \\
\hline 35 patients & 23 & $65 \cdot 7$ & 12 & $34 \cdot 3$ & $3 \cdot 1$ \\
\hline Extended necrosis $(50-100 \%$ of & & & & & \\
\hline pancreas) 42 patients & 7 & $16 \cdot 7$ & 35 & $83 \cdot 3$ & $4 \cdot 9$ \\
\hline
\end{tabular}

the cases with necrotising pancreatitis were identified by ultrasound. Based on the number of correct examinations, the sensitivity was $72.9 \%$; it was not affected by the extent of the pancreatic necrosis. Extensive pancreatic destruction was imaged in only $70.8 \%$ of the cases. A false positive diagnosis of necrotising pancreatitis was arrived at in two of the nine patients with severe acute interstitial pancreatitis.

CLINICAL GRADING

The mean numbers of objective signs listed in Table
6 indicate that necrotising pancreatitis ran a more severe course than acute interstitial pancreatitis and that the clinical severity increased proportionally to the extent of pancreatic necrosis. The clinical variability, however, is considerable. Of the patients with acute interstitial pancreatitis, $43.8 \%$ were classified as having severe pancreatitis (three and more signs). On the other hand, $39 \%$ of the patients with necrotising pancreatitis and $16.7 \%$ of the patients with an extensive necrosis were classified as mild pancreatitis according to the criteria. No deaths occurred among patients with nil to two 
signs. Mortality was $11.3 \%$ in patients with three and more signs.

\section{Discussion}

The routine use of imaging procedures in the diagnosis of acute pancreatitis has substantially contributed to the efficacy of pancreatitis therapy. These procedures permit the visualisation of the pancreas and adjacent tissues and spaces and - by means of follow up examinations - yield an estimate of the dynamics of the inflammatory process. This in turn permits the timely operation of patients with progressive organ destruction.

In our hospital, patients with complicated and severe acute pancreatitis are usually examined with contrast enhanced computed tomography and/or ultrasound in order to identify necrotising pancreatitis. This study reports on the results of these examinations in 93 patients who were investigated prospectively and who were operated because they failed to respond to maximum conservative therapy in the course of pancreatic necrosis or acute biliary disease. The imaging procedures were carried out upon admission and the patients were clinically assessed and classified according to Ranson's objective criteria. ${ }^{7}$ Of the patients so classified, $48 \%$ were secondary referrals from outlying clinics. They were referred to our Pancreas Center because their condition deteriorated to a point which exceeded the therapeutic capacity of the primary admission clinic and a secondary assessment was deemed necessary.

Ten of the criteria were used, fluid sequestration was omitted. Sixty five patients had systemic organ complications, 60 patients had diabetes; hypoalbuminaemia was found in 51 of the 78 patients in whom this parameter was determined. Seventy seven patients had necrotising pancreatitis; 16 patients with severe biliary acute pancreatitis serve as a control group.

The operation was done an average of eight days after admission to the hospital, regardless of whether the referral was primary or secondary. The postoperative mortality was $6 \cdot 5 \%$. Considering the high risk of most of these patients, this rate is relatively low and reflects the benefits of surgical therapy in necrotising pancreatitis. The rationale for the method used is based on the fact that necrotic tissue releases toxic substances and invites bacterial contamination and intraabdominal sepsis. Removal of the tissue debris can prevent this. That is achieved by thorough intraoperative debridement and continuous postoperative lavage of the retroperitoneal space involved in the inflammatory process for as long as there is evidence of necrotic tissue and/or microorganisms in the drainage.
Computed tomography measures the density of structures. Acute pancreatitis is characterised by loss of density, increase in volume and alterations of the contours of the pancreas and - if the process spreads beyond the pancreatic capsule - of retroperitoneal structures. ${ }^{89}$ Necrotising pancreatitis presents as a non-homogeneous density of the pancreas. ${ }^{810}$ Chronic pancreatitis, neoplasia, and fatty degenerative changes can, however, look quite similar. ${ }^{11}$ It is therefore recommended to apply a rapid iv bolus of contrast medium in order to differentiate necrotic portions of the pancreas. ${ }^{10}$ 12-14 After the injection, a phasic change of density can be observed, delimiting necrotic tissue and exudative masses as non-perfused areas which retain their original density. ${ }^{13}$

By using this procedure, we detected $85.1 \%$ of the cases of necrotising pancreatitis. Extensive necrosis $(89.5 \%)$ was assessed with greater accuracy than minor necrosis $(79.3 \%)$, and there was a tendency to underestimate the extent of pancreatic necrosis. On the other hand, small, non-perfused areas were also seen in some of the patients with acute interstitial pancreatitis. Thus a circumscript pancreatic necrosis diagnosed by computed tomography involves the risk that the necrotic area is in fact larger or else that there is no necrosis in the pancreas at all. The imaging of minor perfusion loss therefore necessitates a follow up of examination in order to exclude false positive diagnoses of necrotising pancreatitis. A follow up is advisable at any rate in patients with severe symptoms in cases like this, because pancreatic perfusion in necrotising pancreatitis may be normal initially and fail completely a few hours later. According to our data, the diagnosis of an extensive necrotising process offers a reliability of $90 \%$ and can be accepted as an indication for surgery.

There are only few studies available on the presentation of necrotising pancreatitis in computed tomography investigations. The rates of sensitivity range from $89-100 \%{ }^{815} 16$ Intravenous contrast medium was applied in only one study. In this study, perfusion deficits were noted in eight of nine patients whose necrotising pancreatitis was verified at operation. ${ }^{16}$ Another study carried out without iv contrast medium reported that exudate or haemorrhage were seen in eight of nine patients, ${ }^{15}$ a similar investigation found necrotising pancreatitis presenting as volume increase and in homogeneous structure of the pancreas with exudative masses. ${ }^{8}$ Nonenhanced computed tomography was not able to supply a definite identification and quantification of the necrotising process. Figure 1 shows a picture of exudative pancreatitis as imaged by the nonenhanced computed tomography. The pancreas is 
not seen. Figures 2 and 3 show the demarcation of necrotic pancreatic regions as imaged by the contrast enhanced computed tomography.

Sonography uses the reflection of sound waves at the contact surfaces of structures with different acoustic impedance. ${ }^{17}$ The diagnosis of acute pancreatitis is based on the attributes, size, form, contour, and echogenicity of the pancreas, ${ }^{9} 18$ a decrease of echogenicity being the primary characteristic. ${ }^{19}$
Necrosis presents a non-homogeneous echo which can also be seen in fibrosis and tumours. Obese abdominal walls (which reduce the penetration of sound waves) or meteorism (which absorbs sound waves) render the imaging of the pancreas inaccurate or impossible. ${ }^{17}$ Twenty to sixty five per cent of the studies in patients with acute pancreatitis could not be evaluated because of meteorism. ${ }^{911} 14$

Ultrasound examinations were non-diagnostic be-

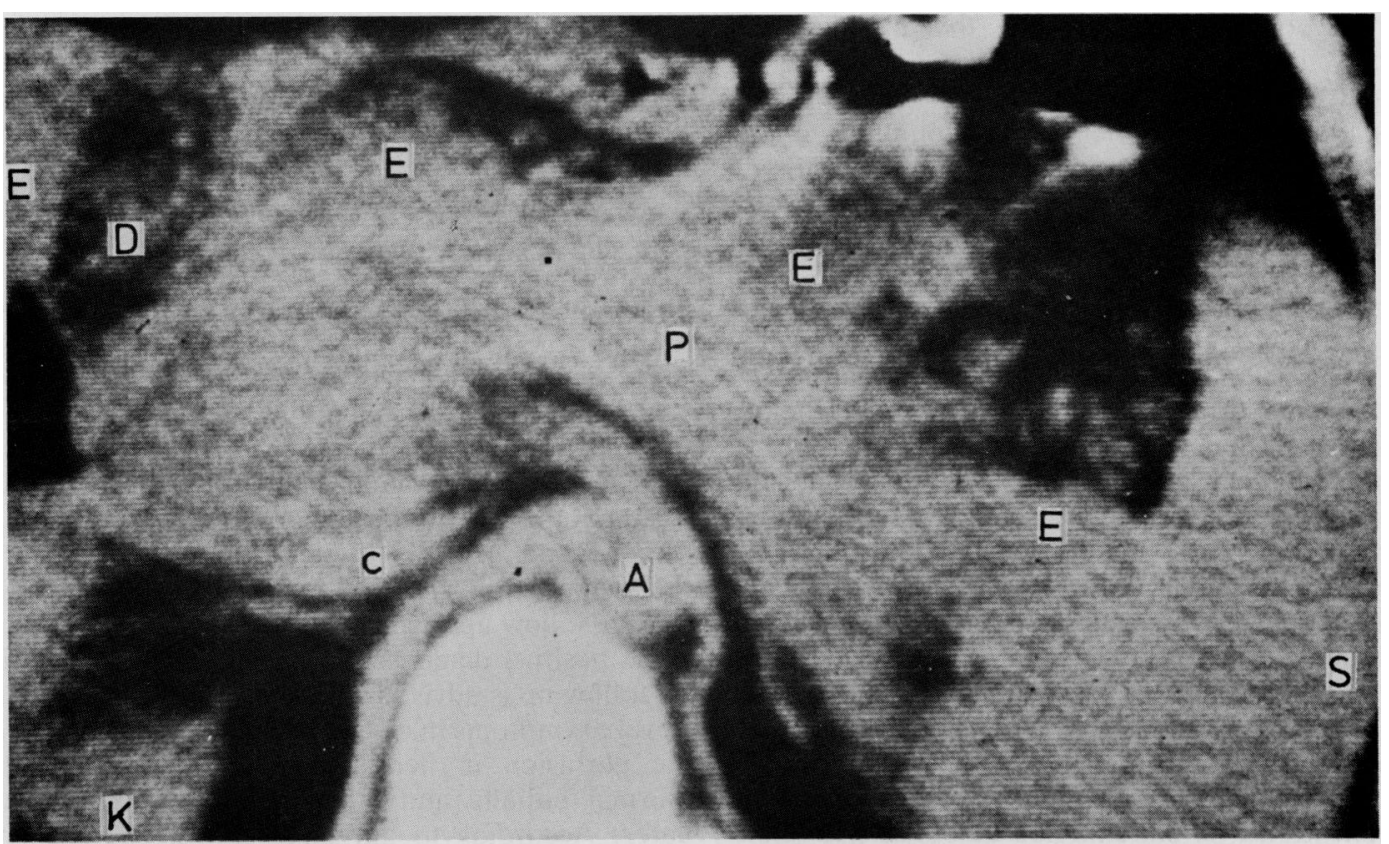

Fig. 1 Acute interstitial pancreatitis with peripancreatic exudate. Computed tomography (CT) before application of contrast medium. The pancreas and exudative masses cannot be differentiated. $P=$ pancreas, $E=e x u d a t e, A=a o r t a$, $D=$ duodenum, $C=V$ cava inf, $K=$ kidney, $S=$ spleen.

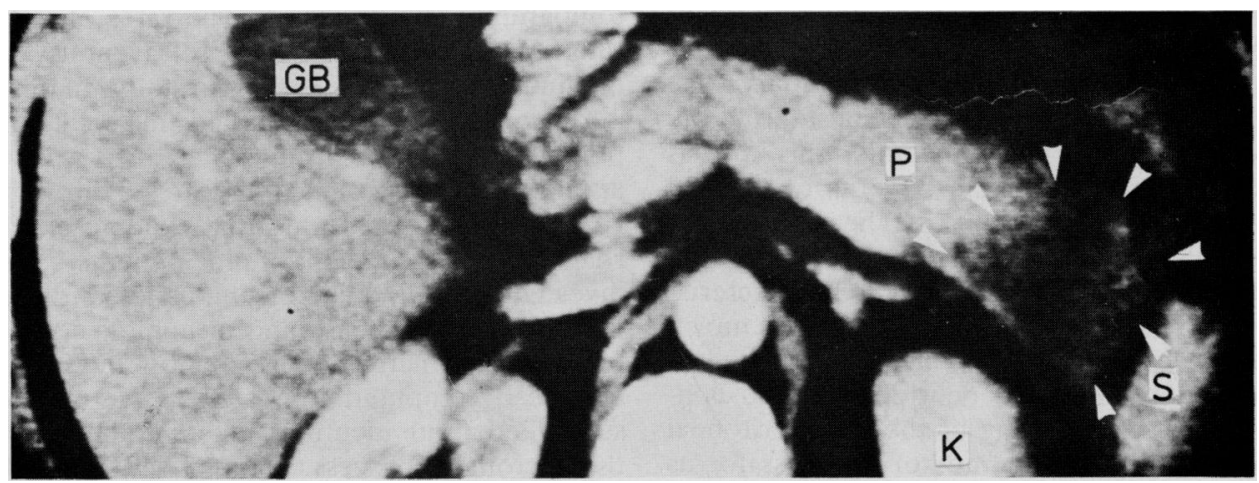

Fig 2 Necrotising pancreatitis. Necrosis of the pancreas tail (contrast-enhanced $C T$ ). $P=$ pancreas, $S=s p l e e n, K=k i d n e y$, $G B=$ gall bladder, white markings = necrotic tail of the pancreas. 


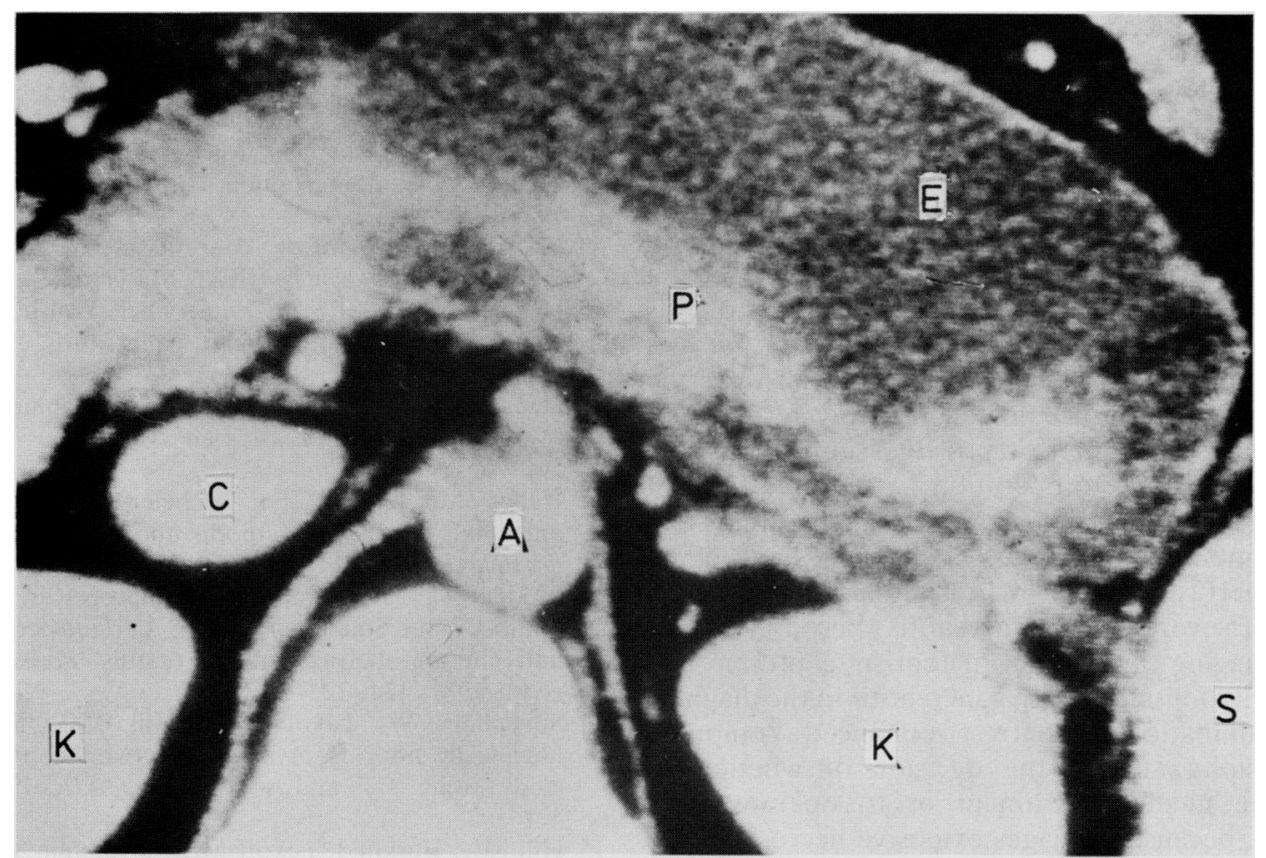

Fig 3 Necrotising pancreatitis. Total involvement of the organ (contrast-enhanced CT). $P=$ pancreas, $E=e x u d a t e$, $A=$ aorta, $C=V$ cava inf, $S=$ spleen, $K=$ kidney.

cause of flatulence in $24.0 \%$ of our patients; the rate was even higher in patients with extensive necrotising pancreatitis. As a consequence, necrotising pancreatitis was determined in only $56.4 \%$ of the cases. The sensitivity of the diagnostic studies was $72.9 \%$. The extent of the necrotic areas was not distinctly visualised, and large pancreatic necroses did not improve the sensitivity.

The diagnostic potential of ultrasound in necrotising pancreatitis was thus considerably less than that of contrast enhanced computed tomography. If all types of acute pancreatitis are considered, both procedures arrive at a sensitivity of $80 \% .{ }^{17}$ This does not include necrotising pancreatitis, however, because there has as yet been no systematic study of its assessment by ultrasound. Ultrasound should preferably be used to ascertain the diagnosis and follow the course of mild acute pancreatitis.

Several attempts have been made to predict the severity of acute pancreatitis. ${ }^{720} 21$ McMahon and coworkers $^{20}$ used diagnostic peritoneal lavage to assess $72 \%$ of the cases of severe acute pancreatitis, $71 \%$ by means of Imrie's ${ }^{21}$ and $82 \%$ by means of Ranson's ${ }^{7}$ criteria. Imrie and associates ${ }^{22}$ reported that they correctly predicted $53 \%$ of the severe attacks by means of diagnostic peritoneal lavage and $61 \%$ by using multiple criteria. ${ }^{21}$ Emphasis is placed on the fact that not all patients which fulfill the criteria of severe pancreatitis actually run a severe course of disease..$^{23}$ The clinical outcome was the main criterium for the predictive correctness of the studies. There has as yet been no systematic study of the relationship between morphological alterations and the clinical criteria.

Although our study does show a correlation between the number of objective signs and morphological progression, $44 \%$ of the patients with acute interstitial pancreatitis were classified as having severe acute pancreatitis, whereas $39 \%$ of the patients with necrotising pancreatitis were categorised as mild pancreatitis. Among the latter were seven patients with a $50-100 \%$ necrosis of the pancreas with the corresponding extra-pancreatic manifestations. Considering the therapeutic implications - conservative management in patients with the mild form, intensive medical care and further therapeutic measures in patients with severe pancreatitis $-8 \%$ of the patients would have been overtreated, whereas $39 \%$ would have been condemned to a prolonged course of disease and the risk of septic complications. With the exception of those cases with mild abdominal complaints lasting only a few days, the discrepancy between clinical and morphological alterations is evidently too prevalent to justify the sole reliance on clinical data in the management of acute pancreatitis. 
The mortality rates in our study showed only a rough correlation with the categories of objective signs and were considerably lower than those stated in a study which emphasises the non-surgical management ${ }^{22}$ of severe acute pancreatitis.

The results of our study make it quite clear that no safe conclusion concerning the degree of morphological alteration in the pancreas can be drawn from the clinical signs and symptoms of acute pancreatitis and, in particular, from Ranson's criteria. This is also supported by the fact that only $60 \%$ of the patients with severe acute pancreatitis referred to us from other hospitals for possible surgical therapy actually required an operation. About one third of the patients recovered with medical treatment and the computed tomography imaging showed no major perfusion deficit. Ultrasound is inadequate in cases of severe acute pancreatitis, because it lacks both imaging capability if meteorism is present and sensitivity for necrotising pancreatitis in the diagnostic examinations. Contrast enhanced computed tomography aids in the decision of whether to continue medical treatment or to operate on a patient, because it images extensive necrosis of the pancreas with high sensitivity. A computed tomography examination showing a minor perfusion deficit requires a follow up to determine whether this was because of a transient disturbance of circulation or the initial stage of progressive pancreatic necrosis.

The paper was presented in part at the Joint Meeting of the American Pancreatic Association and the National Pancreatic Cancer Project, Chicago, Illinois, 8 and 9 November, 1984.

\section{References}

1 Bittner R, Beger HG, Block S, Büchler M. Prognostic indicators in patients with necrotizing pancreatitis. Digestion 1984; 30: 123.

2 Hollender LF, Mayer C, Kauffmann J P, Keller D, Seguin J, Pagliano G. Traitment chirurgical des pancréatites aigues ńecrotico-hémorragiques. $J$ Chir (Paris) 1983; 120: 595-601.

3 Warshaw AL, Imbembo AL, Civetta JM, Daggett WM. Surgical intervention in acute necrotizing pancreatitis. Am J Surg 1974: 127: 484-95.

4 Beger HG, Krautzberger W, Bittner R, Block S, Büchler M. Results of surgical treatment of necrotizing pancreatitis. World J Surg. (In press).

5 Kivilaakso E. Lempinen M, Mäkeläinen A, Nikki, P, Schröder T. Pancreatic resection versus peritoneal lavation for acute fulminant pancreatitis. Ann Surg 1984; 199: 426-31.

6 Klose KJ, Neher M, Kuhn FP, Kümmerle F. Thelen M. Operative Behandlung bei akuter Pankreatitis. Wandel unter dem Einflu $\beta$ von Sonographie und Computertomographie. Dtsch Med Wochenschr 1983; 108: 490)-5.
7 Ranson JHC. Rifkind KM, Roses DF, Fink SD, Eng $\mathrm{K}$, Spencer FC. Prognostic signs and the role of operative management in acute pancreatitis. Surg Gynecol Obstet 1974; 139: 69-81.

8 Haertel M. Tillmann U, Fuchs WA. Die akute Pankreatitis in Computertomogramm. Fortschr Röntgenstr 1979; 130: 525-30.

9 Pfankuchen EJ. Current concepts in pancreatic imaging. Surg Clin North Am 1981; 61: 17-45.

10 Dembner AG, Jaffe CC, Simeone J, Walsh J. A new computed tomographic sign of pancreatitis. AJR 1979; 133: 477-9.

11 Haaga JR, Alfioli RJ. Computed tomographic scanning of the pancreas. Radiol Clin North Am 1977; 15: $367-76$.

12 Heller M, Grabbe E, Bücheler E. Serien-Computertomographie - Methodik und erste Erfahrungen. Fortschr Röntgenstr 1981; 134: 16-21.

13 Mödder U, Friedmann G, Rosenberger J. Wert der Antio-CT für Stadieneinteilung, Verlaufsbeobachtung und Therapie bei akuter Pankreatitis. Fortschr Röntgenstr 1981: 134: 22-7.

14 Silverstein W. Isikoff MB, Hill MC, Barkin J. Diagnostic imaging of acute pancreatitis: prospective study using CT and sonography. AJR 1981; 137: 497-502.

15 Hill MC, Barkin J, Isikoff MB, Silverstein W, Kalser M. Acute pancreatitis: clinical vs CT findings. $A J R$ 1982: 139: 263-9.

16 Kivisaari L. Somer K. Standertskjöld-Nordenstam C-G, Schröder T, Kivilaaksho E, Lempinen M. Early detection of acute fulminant pancreatitis by contrastenhanced computed tomography. Scand J Gastroenterol 1983; 18: 39-41.

17 Lackner K. Frommhold H. Grauhoff H, et al. Wertigkeit der Computertomographie und der Sonographie innerhalb der Pankreasdiagnostik. Fortschr Röntgenstr 1980; 132: 509-13.

18 Lawson TL. Sensitivity of pancreatic ultrasonography in the detection of pancreatic disease. Radiology 1978; 128: 733-6.

19 Braun B. Sonographische Untersuchungen bei akuter Pankreatitis. In: Schönborn $\mathrm{H}$, ed. Intensivmedizin bei gastroenterologischen Erkrankungen. Stuttgart: Thieme Verlag. 1980: 105-11.

20 Mc Mahon MJ, Playforth MJ, Pickford IR. A comparative study of methods for the prediction of severity of attacks of acute pancreatitis. Br J Surg 1980; 67: 22-5.

21 Imrie CW. Benjamin IS, Ferguson JC, et al. A singlecentre double-blind study of Trasylol in primary acute pancreatitis. BrJ Surg 1978; 65: 337-41.

22 Corfield AP, Cooper MM, Williamson RCN et al. Prediction of severity in acute pancreatitis: prospective comparison of three prognostic indices. Lancet 1985; 8452: 403-7.

23 Ranson JHC. Acute pancreatitis - Where are we? Surg Clin North Am 1981: 61: 55-70.

24 Kauste A. Höckerstedt K. Ahonen J, Tervaskari H. Peritoneal lavage as a primary treatment in acute fulminant pancreatitis. Surg Gynecol Obstet 1983; 156: $458-63$. 